\title{
Trombosis venosa mayor asociada a catéter de hipotermia terapéutica en un paciente con paro cardiorrespiratorio recuperado: comunicación de un caso y revisión de la literatura
}

\author{
JAIME RETAMAL ${ }^{1,2, a}$, JEAN BACHLER ${ }^{2, b}$, RICARDO MEJÍA ${ }^{2, b}$, \\ ORLANDO CONCHA ${ }^{3, \mathrm{c}}$, MAX ANDRESEN ${ }^{1,2, \mathrm{a}}$
}

\section{Venous thrombosis secondary to catheter insertion for hypothermia after cardiac arrest. Report of one case}

To improve survival and reduce neurological injury, the use of mild hypothermia following cardiac arrest has been recommended. We report a 65 years old woman who presented an out-of-hospital ventricular fibrillation and cardiac arrest. The patient was comatose following initial resuscitation and was admitted into the ICU, where cooling was initiated using an intravascular catheter. After 48 hours, rewarming was initiated. Although no neurological impairment was observed, physical examination of the right inguinal area and echo-Doppler examination revealed an extensive catheterrelated thrombophlebitis with right ileocaval vein occlusion., with high risk of masive and life threatening pulmonary embolism. We report a clinical case and review the literature to point out the need for a high index of diagnostic suspicion of deep venous thrombosis in these specific setting.

(Rev Med Chile 2011; 139: 1201-1205).

Key words: Catheters; Hypothermia; Venous thrombosis.

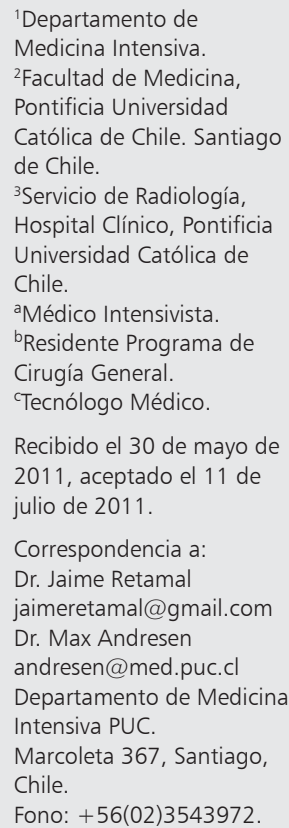

L a mayoría de los pacientes que sufren un paro cardiorrespiratorio (PCR) no sobreviven. Entre los sobrevivientes, la recuperación neurológica completa sólo ocurre entre el 6 y 23\% de los casos. Con el fin de mejorar la sobrevida y reducir la injuria neurológica, varios estudios han recomendado recientemente el uso de la hipotermia moderada luego de un PCR.

Nosotros comunicamos el caso de una mujer de 65 años quien presentó un PCR en fibrilación ventricular extrahospitalario. La paciente se presentó en coma luego de la resucitación inicial siendo admitida a la Unidad de Cuidados Intensivos (UCI) donde se instauró la hipotermia mediante un catéter intravascular. Luego de 48 horas se inicio el recalentamiento y se evaluó el estado neurológico. Aunque no se encontraron alteraciones neurológicas, el examen físico de la zona inguinal derecha y una ecotomografía Doppler reveló una extensa trombosis relacionada a la inserción del catéter con oclusión de vena ilíaca derecha y cava inferior

La hipotermia terapéutica moderada se ha transformado en una intervención reconocida luego de un PCR, sin embargo, pueden ocurrir complicaciones relacionadas al catéter, como la que describimos.

La incidencia de paro cardiorrespiratorio (PCR) extrahospitalario es alta, reportándose aproximadamente 425.000 casos por año en USA y Europa ${ }^{1,2}$. La mayoría de estos pacientes no sobreviven, y aquellos que lo hacen y que son 
trasladados al hospital sólo 6-23\% son dados de alta sin secuelas neurológicas ${ }^{3}$.

El uso de hipotermia terapéutica se inicia en la década de los 50. Sin embargo, ha adquirido mayor connotación durante los últimos años, publicándose abundante información en múltiples estudios experimentales y clínicos que demuestran que el uso de hipotermia leve tendría efecto neuroprotector ${ }^{4}$.

Existen dos estudios randomizados en seres humanos que demuestran mejoría en el resultado neurológico así como una disminución en la mortalidad en pacientes que son sometidos a hipotermia leve por 12 a 24 horas luego de sufrir un PCR extra-hospitalario secundario a fibrilación ventricular y que posterior a la resucitación inicial persisten comatosos ${ }^{5,6}$

El uso de hipotermia leve (32-34') ha sido establecido durante los últimos años, como recomendación clase I para casos de PCR extrahospitalarios de pacientes inconscientes que hayan recuperado la circulación espontánea luego de un episodio de fibrilación ventricular recuperada. ${ }^{2,7}$ Sin embargo, aún no queda claro el sistema de enfriamiento ideal, el momento de inicio ni el ritmo de enfriamiento. Como tampoco si es correcto ampliar las indicaciones de HT a otras causas de PCR.

Para uso clínico, existen disponibles varios sistemas de control de la temperatura, desde sistemas de enfriamiento externo hasta sistemas de enfriamiento intravascular ${ }^{4}$. Estos últimos son los más ampliamente difundidos, dado que permiten un mayor control y efectividad para regular la temperatura.

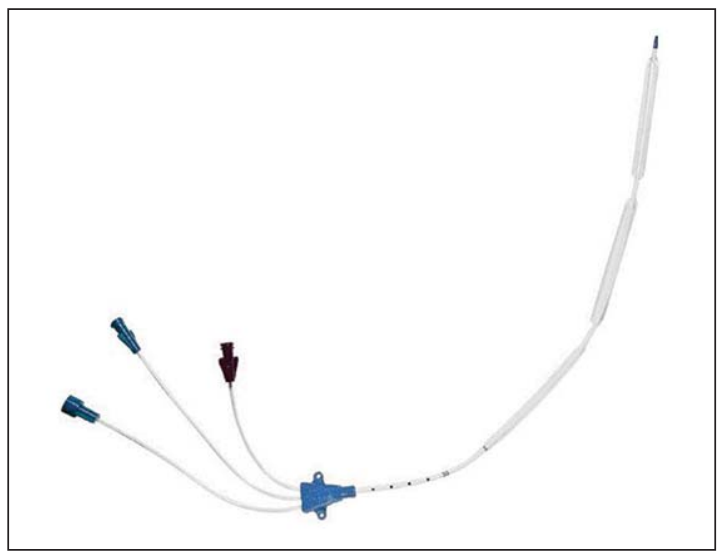

Figura 1. Catéter Icy®.
En nuestra unidad se usa el sistema CoolGard $3000^{\circledR}$ (Alsius Corporation, Irvine, CA, USA) (Figura 2), el que utiliza un catéter venoso central de acceso femoral en el caso de realizar hipotermia (catéter Icy ${ }^{\circledR}$ (Figura 1) y yugular o subclavio para realizar normotermia (catéter CoolLine ${ }^{\circledR}$ ). Ambos catéteres utilizan un sistema cerrado de recirculación de solución salina fría por una serie de globos que se despliegan desde el catéter una vez que este se ubica en posición intravascular ${ }^{8}$.

La inserción de catéteres de hipotermia conlleva los riesgos inherentes a la instalación de cualquier catéter venoso central (errores de colocación, sangrado, infección, trombosis venosa, neumotórax, y el daño de estructuras cercanas), además de los riesgos y complicaciones de la hipotermia (inmunosupresión, sangrado, alteraciones metabólicas y de la conducción eléctrica cardiaca, entre otros). Las complicaciones relacionadas con el uso del sistema CoolGard ${ }^{\circledR}$ son pocas, y no existe evidencia que muestre diferencias categóricas en las tasas de complicación entre este tipo de catéteres y el resto ${ }^{9,10}$. Se han comunicado escasos reportes en la literatura mundial de trombosis venosa en relación al catéter de hipotermia. A continuación revisaremos un caso clínico de una paciente sometida a HT complicada con una ex-

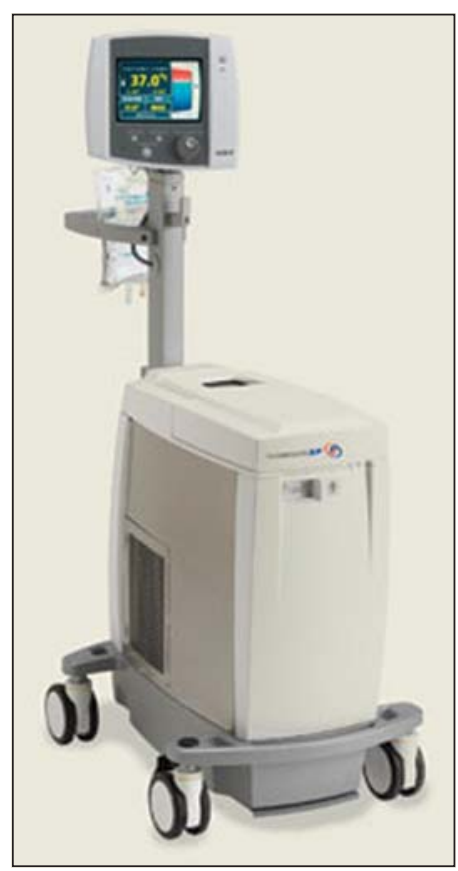

Figura 2. Sistema regulador de temperatura Coolgard $3000 \AA$. 


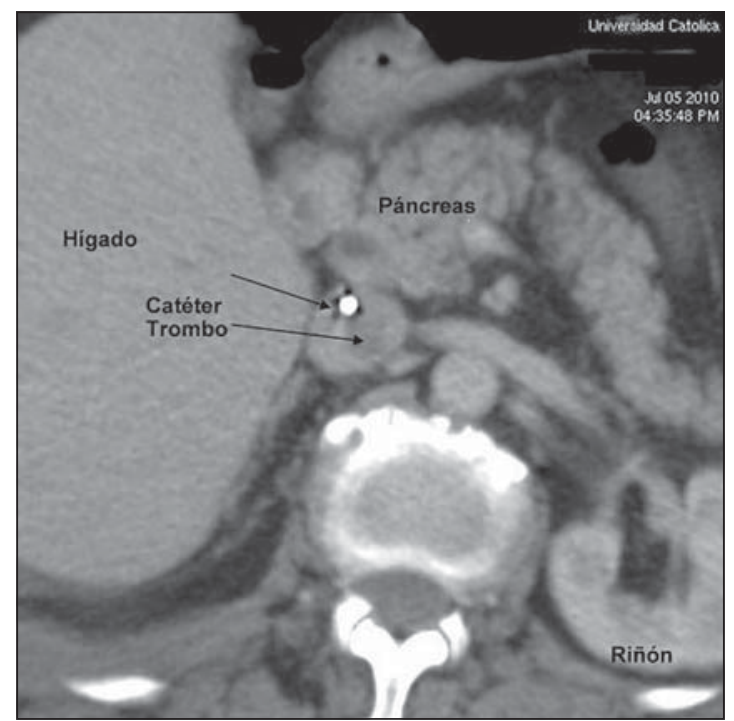

Figura 3. Imagen por tomografía computada que muestra trombo en relación al catéter Icy® en la vena cava inferior a nivel hepático.

tensa trombosis ilíaco-cava asociada a la inserción del catéter de hipotermia en vena femoral, la que de no sospecharse, y tratarse oportunamente la pone en riesgo vital.

\section{Objetivo}

Presentar un caso clínico y revisar los beneficios, indicaciones y potenciales efectos adversos, específicamente de trombosis venosa, con el uso de hipotermia leve en pacientes con PCR recuperado.

\section{Caso clínico}

Paciente sexo femenino, 65 años de edad, secretaria en centro médico, con antecedentes de hipertensión arterial esencial en tratamiento farmacológico con Losartán.

Presentó PCR presenciado en su lugar de trabajo; en el mismo lugar se iniciaron maniobras de recuperación cardiopulmonar (RCP) básico por operadores no médicos entrenados (compañeros de trabajo). Al cabo de aproximadamente 5 minutos las maniobras fueron manejadas por anestesistas que llegan al lugar, las que se realizaron por aproximadamente 15 minutos. Cuando se contó con desfibrilador bifásico, se constató fibrilación ventricular (FV). Se procedió a desfibrilación con

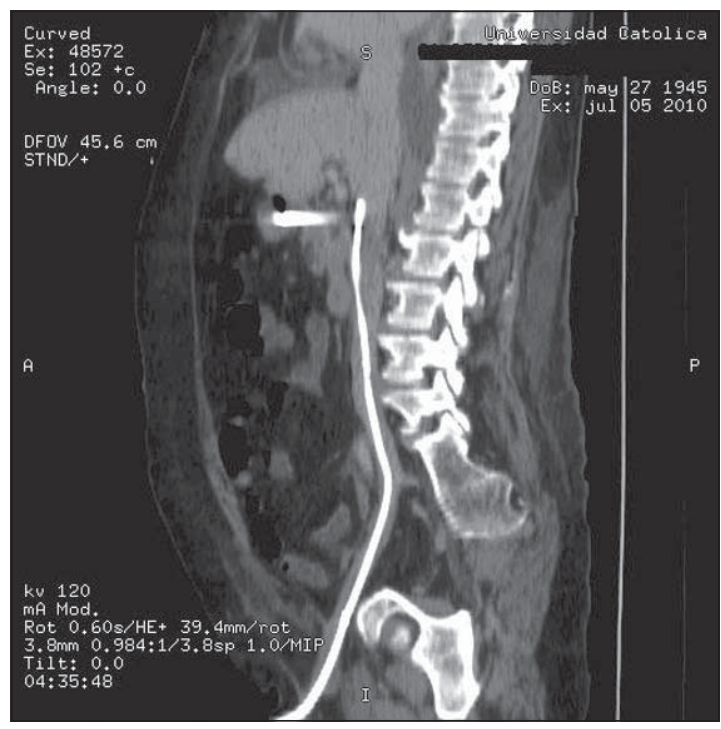

Figura 4. Imágenes de tomografía computada que muestra la inserción femoral del catéter Icy® a través de la vena cava hasta nivel hepático.

200 Joules. Se mantuvieron maniobras de reanimación por dos minutos y se procedió a reanalizar ritmo, observándose ritmo sinusal. Se verificó pulso, el cual se encontraba presente aunque débil. Se continuó RCP y se realizó traslado a Servicio de Urgencia. Durante su traslado la paciente presentó 3 nuevos episodios de FV por lo que se desfibriló sucesivamente. Durante este período se administraron en total $4 \mathrm{mg}$ de adrenalina, $2 \mathrm{mg}$ atropina y $5 \mathrm{mg}$ sulfato magnesio.

A su ingreso al Servicio de Urgencias de nuestro Hospital se encontraba en ritmo sinusal, con ventilación espontánea. Se procedió a la intubación orotraqueal, se administraron $2.000 \mathrm{cc}$ de solución salina al $0,9 \%$ a una temperatura de $4{ }^{\circ} \mathrm{C}$ y fue trasladada a la Unidad de Pacientes Críticos.

En su examen neurológico de ingreso destacaba "Glasgow Coma Scale" (GCS) 3 puntos, vagabundeo ocular, midriasis bilateral y reflejo plantar extensor bilateral. Se realizó instalación de un catéter de hipotermia Icy ${ }^{\circledR}$ (Alsius Corporation, Irvine, California) vía vena femoral derecha. Se inició hipotermia intravenosa $1 \mathrm{~h} 30 \mathrm{~min}$ luego de PCR, con una temperatura objetivo de $33^{\circ}$ $\mathrm{C}$ a una tasa de enfriamiento máximo. Se logró objetivo a las $4 \mathrm{~h}$ post PCR, manteniéndose esta temperatura por $48 \mathrm{~h}$. Posteriormente se inició recalentamiento a una tasa de $0,1^{\circ} \mathrm{C} / \mathrm{h}$ las primeras 
8 h y luego $0,2^{\circ} \mathrm{C} / \mathrm{h}$ para lograr temperatura $36^{\circ} \mathrm{C}$ en aproximadamente $18 \mathrm{~h}$.

Durante el período de hipotermia la paciente presentó al menos 2 episodios de fibrilación auricular, uno de los cuales requirió cardioversión eléctrica. Se descartó origen isquémico de PCR. Se realizó ECO-cardiografía que demostró miocardiopatía hipertrófica con severa disfunción sistólica y obstrucción dinámica del tracto de salida asociado a insuficiencia mitral moderada a severa.

Evolucionó con falla respiratoria aguda precoz, secundaria a neumonía grave y síndrome de distress respiratorio agudo (SDRA), de difícil manejo por depender de precarga para sostener hemodinamia, intolerancia a vasodilatadores, diuréticos y PEEP moderado a alto, en contexto de pulmones con alto contenido de agua.

Al cuarto día de evolución se suspende sedación, para realizar evaluación neurológica. La paciente presentó apertura ocular espontánea, obedecía órdenes, movilizaba 4 extremidades, y no presentaba signos de focalidad neurológica.

Al quinto día, habiéndose mantenido con profilaxis antitrombótica con enoxaparina, se decidió retiro del catéter de hipotermia. Previo al retiro se realizó ecografía inguinal derecha y de extremidades inferiores, observándose extensa trombosis venosa ilio-femoral derecha. Se complementó estudio con AngioTAC evidenciándose progresión de trombo hasta vena cava intrahepática (Figuras 3 y 4) Se inició anticoagulación con heparina de bajo peso molecular. $\mathrm{Al} 11^{\circ}$ día de hospitalización y dada la imposibilidad técnica de instalar un filtro de vena cava inferior caudal al trombo, se procedió al retiro del catéter de hipotermia bajo visión ecográfica. Se realizó Angio-TAC de control que mostró pequeño tromboembolismo pulmonar (TEP) subsegmentario basal derecho. Se manejó con anticoagulación con heparina.

Extubación exitosa día 25 de evolución, trasladada a hospital de base para implante de desfibrilador y continuar estudio de cardiopatía de base para eventual resolución quirúrgica.

\section{Discusión}

Existe abundante información sobre las alteraciones de la coagulación que se pueden desarrollar en un paciente sometido a hipotermia, se describen: alteraciones de la función plaquetaria, disminución en el número de plaquetas, alteraciones en la producción y cinética de los factores de coagulación; sin embargo, estos estudios han sido realizados in vitro ${ }^{4}$. Llama la atención que en ninguno de los trabajos que han evaluado el uso de hipotermia en TEC, PCR o HSA se haya comunicado un incremento significativo en los casos de sangrado clínicamente importante. Por esta razón este riesgo impresiona teórico o clínicamente importante sólo para casos de hipotermia bajo $33^{\circ} \mathrm{C}$.

Por otro lado, han aparecido algunos reportes de casos aislados de trombosis venosa asociada al uso de catéteres de hipotermia ${ }^{9-11}$. Al revisar las grandes casuísticas de pacientes sometidos a este tratamiento, no se establece la aparición de trombosis venosa como outcome importante a evaluar, sin embargo, existen comunicaciones de casos aislados con esta complicación. Pichon y cols, revisan una serie de 34 pacientes sometidos a HT de $33^{\circ} \mathrm{C}$ por un período promedio de 37 horas, realizando Doppler sistemáticamente a todos los pacientes una vez retirado el catéter, no encontraron casos de trombosis, posterior al retiro del catéter, por criterio clínico ni ultrasonográfico ${ }^{12}$.

Taylor y cols, publicaron su experiencia con 11 pacientes que usaron catéter Icy, describiendo sólo un caso de tromboembolismo pulmonar y trombosis venosa asociada al catéter, no se describe en este caso el tiempo de uso del catéter ${ }^{9}$.

Lau y cols, publican un caso de trombosis asociada a catéter Quattro ${ }^{\circledR}$ (Zoll Medical Corporation, Chelmsford, MA) en este caso se utilizó durante 24 horas, se utilizo tromboprofilaxis con heparina. En este caso el catéter utilizado posee cuatro globos ${ }^{11}$.

Prunet y cols, publicaron en 2010 otros dos casos, destacando que ambos pacientes mantuvieron el dispositivo in situ durante siete y diez días respectivamente, siendo retirados una vez que se pesquisaron las trombosis clínicamente y se confirmaron con estudios radiológicos ${ }^{10}$.

Es importante destacar que en dos de los cuatro casos presentados la duración del uso del dispositivo fue igual o superior a una semana. El fabricante de los catéteres de hipotermia recomienda su recambio si el uso se prolonga más de siete días ${ }^{13}$.

Esta complicación torna mayor importancia en la medida que se amplíe el uso a pacientes neurocríticos en donde el uso de anticoagulación puede adquirir mayor morbilidad por sangrados en el sistema nervioso central. 
Se ha reportado incidencias sorprendentemente altas de trombosis venosas, en pacientes con catéteres venosos centrales instalados más de siete días, que oscilan entre 33 y $67 \%{ }^{14}$. Así, los factores propios del CVC que inducen la formación de trombos son: disrupción del endotelio venoso y alteración del flujo sanguíneo laminar, además del tamaño y diámetro del dispositivo.

El largo de los catéteres Icy ${ }^{\circledR}$ y Quattro ${ }^{\circledR}$ oscila entre 38 y 45 centímetros y el diámetro es de 9,3 French en ambos casos. Además es probable que los globos que se despliegan desde el catéter puedan distorsionar aún más el flujo laminar y dañar el endotelio, favoreciendo el desarrollo de trombosis.

Aun no existen datos que objetiven diferencias significativas en la incidencia de trombosis con este tipo de catéteres, sin embargo, los casos reportados hacen necesario pensar en este tipo de complicaciones cada vez que se usen o se piense en su retiro, debiendo tener un alto índice de sospecha. Evaluando además, según disponibilidad, la realización de ecotomografía Doppler venosa rutinaria previo al retiro o más aún cuando se prolongue el uso del catéter más allá de siete días.

\section{Referencias}

1. Atwood C, Eisenberg MS, Herlitz J, Rea TD. Incidence of EMS-treated out-of-hospital cardiac arrest in Europe. Resuscitation 2005; 67 (1): 75-80.

2. Rea TD, Eisenberg MS, Sinibaldi G, White RD. Incidence of EMS-treated out-of-hospital cardiac arrest in the United States. Resuscitation 2004; 63 (1): 17-24.

3. Holzer M, Behringer W. Therapeutic hypothermia after cardiac arrest. Curr Opin Anaesthesiol 2005; 18 (2): 1638.

4. Polderman KH. Mechanisms of action, physiological effects, and complications of hypothermia. Crit Care Med 2009; 37 (7 Suppl): S186-202.
5. Mild therapeutic hypothermia to improve the neurologic outcome after cardiac arrest. N Engl J Med 2002; 346 (8): 549-56.

6. Bernard SA, Gray TW, Buist MD, Jones BM, Silvester W, Gutteridge G, SmithTreatment of comatose survivors of out-of-hospital cardiac arrest with induced hypothermia. N Engl J Med 2002; 346 (8): 557-63.

7. Peberdy MA, Callaway CW, Neumar RW, Geocadin RG, Zimmerman JL, Donnino M, et al. Part 9: post-cardiac arrest care: 2010 American Heart Association Guidelines for Cardiopulmonary Resuscitation and Emergency Cardiovascular Care. Circulation 2010; 122 (18 Suppl 3): S768-86.

8. Al-Senani FM, Graffagnino C, Grotta JC, Saiki R, Wood D, Chung W, et al. A prospective, multicenter pilot study to evaluate the feasibility and safety of using the CoolGard System and Icy catheter following cardiac arrest. Resuscitation 2004; 62 (2): 143-50.

9. Taylor EE, Carroll JP, Lovitt MA, Petrey LB, Gray PE, Mastropieri CJ, et al. Active intravascular rewarming for hypothermia associated with traumatic injury: early experience with a new technique. Proc Bayl Univ Med Cent 2008; 21 (2): 120-6.

10. Prunet B, Lacroix G, Bordes J, Poyet R, D'Aranda E, Goutorbe P. Catheter related venous thrombosis with cooling and warming catheters: two case reports. Cases J 2009; 2: 8857.

11. Lau E, Bajzer C, Menon V. Inferior vena cava thrombus associated with intravascular cooling catheter. Resuscitation 2010; 81 (11): 1457-8.

12. Pichon N, Amiel JB, Francois B, Dugard A, Etchecopar C, Vignon P. Efficacy of and tolerance to mild induced hypothermia after out-of-hospital cardiac arrest using an endovascular cooling system. Crit Care 2007; 11 (3): R71.

13. Polderman $\mathrm{KH}$, Callaghan J. Equipment review: cooling catheters to induce therapeutic hypothermia? Crit Care 2006; 10 (6): 234.

14. Polderman KH, Girbes AJ. Central venous catheter use. Part 1: mechanical complications. Intensive Care Med Jan 2002; 28 (1): 1-17. 